Atomic Artillery and the Atomic Bomb By John Kellock Robertson. Pp. xii $+173+8$ plates. (New York: D. Van Nostrand Co. Inc.; London : Macmillan and Co. Ltd., 1945.) 12s. 6d.net.

T $O$ the serious student of science this is a disappointing book. It is essentially a reprint of the author's "Atomic Artillery" with two added chapters on nuclear fission and the atomic bomb. The additional material is very slight and contains at least one unfortunate misprint, and several misstatements of fact.

In 1937, when the first edition appeared, this book probably served a useful purpose in directing the attention of the semi-technical reader to nuclear physics, at that time still an academic discipline of little practical value. So much excellent material has now been published about the basis of atomic energy, particularly in the United States, and so much has been done to cater for public interest in nuclear physics, that the present work reads as a pleasantly told but rather old-fashioned story. Like the official Smyth Report, the account given of the fission process fails to acknowledge the essential contribution to the subject made by Joliot and his colleagues in France. Their discovery of the neutrons emitted in the fission process was the crucial observation which made the chain reaction practicable. Similarly, the descriptions given of equipment used in nuclear physics, such as the Van de Graaff generator, or cyclotron, are searcely in line with modern practice.

Notwithstanding these criticisms this book will be read with profit by many who wish to understand something of the romantic story of the growth of nuclear physics and its exploitation. The style is simple and stimulating, and the errors and omissions which occur will be noticed by few who are not nuclear physicists.

M. L. Oliphant

\section{Radio Receiver Design}

By Dr. K. R. Sturley. Part 2: Audio Frequency Amplifiers, Television and Frequency Modulated Receiver Design. Pp. $x v+480$. (London : Chapman and Hall, Ltd., 1945.) 28s. net.

$\mathrm{T}$ HIS book forms the second part of a comprehensive treatise on the principles of design of radio receivers, the first part of which was reviewed in Nature of June 12,1943 , p. 657. Part 2 preserves continuity with Part 1 to the extent that the chapters are numbered 9 to 16 , and it completes the process of following the progress of the signal from the aerial through the receiver to the onput or loudspeaker.

In accordance with this scheme, the first three chapters of the present volume deal with audio frequency amplification, the power output stage and power supplies. Next, the necessary controls on a receiver are analysed in terms of their function of controlling automatically the gain and tuning of the receiver; while Chapter 14 reviews in some detail the definitions and specifications appropriate to the measurement of overall performance of receivers. The last two chapters in the book are each practically self-contained and are devoted to the special features associated with the reception of frequency modulated and television transmissions respectively.

The author's clear analytical style, with appropriate graphical illustration and numerical examples, has been maintained throughout this volume, which with its companion, Part 1, forms a most useful work of reference for the radio engineer and designer. In addition to the actual material in the book itself, each chapter ends with a most helpful selected bibliography, the total number of references in the present volume being nearly two hundred. The reader is thus provided with a direct key to the most useful literature, which is scattered over a wide variety of publications.

\section{Poultry Keeping for $\mathrm{AH}$}

By Harold Perkins. Pp. $66+8$ plates. (Worcester : Littlebury and Co. Ltd., n.d.) 7s. 6d. net.

7 HIS book can be looked upon as only a brief 1 introduction to the subject of poultry-keeping for beginners. The author has obviously had wide practical experience, and deals in a non-technical manner with matters, mostly based on personal experiences, which sometimes are not in line with scientific facts. His contact with domestic poultrykeepers has enabled him to appreciate their difficulties, and these are dealt with in a helpful way, punctuated by entertaining anecdotes.

The author admits that he does not attempt to go deeply into any particular branch and has mainly generalized, advising the reader to seek further information in more specialized works. In this connexion, it would have been helpful if a bibliography of such works had been appended.

Better use might have been made of the paper space available; on p. 23 barely one third of the space is occupied by a short paragraph headed "Breeding", which the author might well have expanded, although he states: "Of breeding I don't want to say much because there is so much to be said" ! The subject of feeding is also very sketchily and inadequately covered.

The book is badly arranged, for under the heading of "Diseases" are included such subjects as "egg grading and washing", "the future of D.P.K. Clubs", and other irrelevant items. The illustrations, however, are attractive and the type good. D. J. G. BI.ACK

\section{Active Nitrogen-A New Theory}

By Prof. S. K. Mitra. (Joykissen Mookerje日 Medal Lecture for 1945.) Pp. vi + 73. (Calcutta: Indian Association for the Cultivation of Science, 1945.) n.p. 7 HE afterglow of nitrogen in a discharge tube was first observed in 1884, and attempts to explain it have been made at intervals for the last thirty-five years. In the first, and larger, part of this book the observations on active nitrogen during this period are reviewed. This part is well and stimulatingly written ; the discussion of the work of Lord Rayleigh, Willey, Kaplan and others on the production, decay and chemical effects seems particularly well done and makes interesting reading; on the spectroscopic side Prof. Mitra seems on slightly less firm ground. He appears to have missed the work of Spealman and Rodebush showing that the yellow-green air afterglow is due to reaction between nitric oxide and atomic oxygen, not between nitrogen peroxide and ozone as stated in the book; but the bibliography on the nitrogen afterglow itself seems fairly complete.

Existing theories of the afterglow are briefly stated and receive some well-justified criticism. The second part of the book gives Prof. Mitra's new theory that the afterglow is due to recombination of ionized nitrogen molecules with free electrons. The case for this simple theory is put clearly; but it seems doubtful whether it can explain all the facts, and it is unlikely to receive general acceptance. The chief value of the book lies in its clear readable summary of experimental work.

A. G. GAYDON 